\title{
Correction to: Longitudinal PET Imaging to Monitor Treatment Efficacy by Liposomal Irinotecan in Orthotopic Patient-Derived Pancreatic Tumor Models of High and Low Hypoxia
}

\author{
Manuela Ventura, ${ }^{1}$ Nicholas Bernards, ${ }^{1}$ Raquel De Souza, ${ }^{1}$ Inga B. Fricke, ${ }^{1}$ \\ Bart S. Hendriks, ${ }^{2}$ Jonathan B. Fitzgerald, ${ }^{2}$ Helen Lee, ${ }^{2}$ Stephan G. Klinz, ${ }^{2,3}$ \\ Jinzi Zheng $\mathbb{B}^{1,4}$ \\ ${ }^{1}$ TECHNA Institute for the Advancement of Technology for Health, University Health Network, Toronto, Ontario, Canada \\ ${ }^{2}$ Merrimack Pharmaceuticals, Inc., Cambridge, MA, USA \\ ${ }^{3}$ Ipsen Bioscience, Cambridge, MA, USA \\ ${ }^{4}$ Institute of Biomaterials and Biomedical Engineering, University of Toronto, Toronto, Ontario, Canada
}

Correction to: Mol Imaging Biol (2020)

https://doi.org/10.1007/s11307-019-01374-x

The article "Longitudinal PET Imaging to Monitor Treatment Efficacy by Liposomal Irinotecan in Orthotopic Patient-Derived Pancreatic Tumor Models of High and Low Hypoxia," written by Manuela Ventura et al., was originally published Online First without Open Access. After publication in volume 22 , issue 3, pages 653-664 the author decided to opt for Open Choice and to make the article an Open Access publication. Therefore, the copyright of the article has been changed to (C) The Author(s) 2019 and the article is forthwith distributed under the terms of the Creative Commons Attribution 4.0 International License, which permits use, sharing, adaptation, distribution and reproduction in any medium or format, as long as you give appropriate credit to the original author(s) and the source, provide a link to the Creative Commons license, and indicate if changes were made. The images or other third party material in this article are included in the article's Creative Commons license, unless indicated otherwise in a credit line to the material. If material is not included in the article's Creative Commons license and your intended use is not permitted by statutory regulation or exceeds the permitted use, you will need to obtain permission directly from the copyright holder. To view a copy of this license, visit http:// creativecommons.org/licenses/by/4.0.

Publisher's Note Springer Nature remains neutral with regard to jurisdictional claims in published maps and institutional affiliations.

The online version of the original article can be found at https://doi.org/ 10.1007/s11307-019-01374-x 